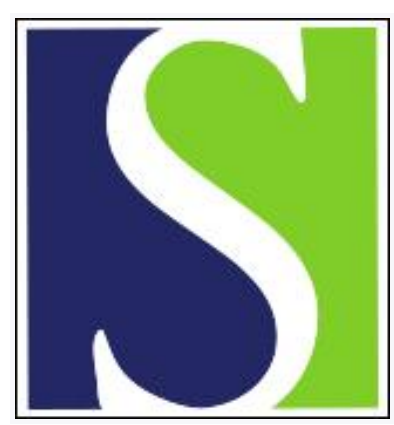

Scand J Work Environ Health 1994;20(5):339-344

https://doi.org/10.5271/sjweh.1388

Issue date: 01 Oct 1994

Incidence of cancer among workers in Norwegian hydroelectric power companies.

by Tynes T, Reitan JB, Andersen A

Affiliation: Cancer Registry of Norway, Institute of Epidemiological Cancer Research, Oslo.

This article in PubMed: www.ncbi.nlm.nih.gov/pubmed/7863297

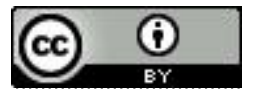




\title{
Incidence of cancer among workers in Norwegian hydroelectric power companies
}

\author{
by Tore Tynes, MD, ${ }^{1}$ Jon B Reitan, MD, ${ }^{2}$ Aage Andersen ${ }^{1}$
}

TYNES T, REITAN JB, ANDERSEN A. Incidence of cancer among workers in Norwegian hydroelectric power companies. Scand J Work Environ Health 1994;20:339_-44.

\begin{abstract}
OBJEctives - The goal of this study was to examine whether exposure to electric or magnetic fields is related to cancer.

METHODs - The study cohort consisted of 5088 men who had worked for at least one year between 1920 and 1991 for any of eight participating companies which produce and distribute hydroelectric power in Norway. The occupational exposure of these workers included extremely low-frequency electromagnetic fields. Incident cancer cases identified from the Cancer Registry of Norway were analyzed on the basis of the standardized incidence ratio with the Norwegian male population as reference.

REsulss - The incidence of cancer was close to unity for the cohort. The standardized incidence ratio for lymphoma was below unity, whereas those for leukemia and brain tumors were similar to those expected. Calculated cumulative exposure to electric or magnetic fields was not associated with the incidence of leukemia or brain tumors, but an excess of malignant melanoma was shown for the highest category of magnetic field exposure. An analysis of combined possible exposure to oils containing polychlorinated biphenyls and exposures to magnetic fields or possible exposure to electric sparks gave standardized incidence ratios of 265 and 280 , respectively, for the higher exposure category. Conclusions - These results do not support the assumption of a possible association between exposure to electromagnetic fields and leukemia and brain tumors. The possible association between exposure to polychlorinated biphenyls or magnetic fields and risk of malignant melanoma should be further evaluated in future studies.
\end{abstract}

KEY TERMS - brain tumor, cohort, electromagnetic fields, leukemia, malignant melanoma, occupational exposure.

Public interest in a possible association between exposure to extremely low-frequency (ELF) electromagnetic (EM) fields and cancer has increased over the last decade. Several epidemiologic studies have suggested an increased risk for cancer, particularly leukemia and brain tumors, in various categories of "electrical occupations."

Interpreting studies of workers exposed to EM fields has been especially difficult because of the lack of historical exposure data and biological support for the hypothesis that occupational exposure to ELF fields in the $50-60 \mathrm{~Hz}$ range can enhance cancer development. Furthermore, the respective roles of electric and magnetic fields have not been established, the results show no homogeneous pattern, and reviewers have suggested confounding factors and publication bias as explanations for the observed excess risks $(1,2)$. Currently, there is no clear experimental evidence to support any single interaction mechanism through which ELF fields could influence

1 Cancer Registry of Norway, Institute of Epidemiological Cancer Research, Oslo, Norway.

2 Norwegian Radiation Protection Authority, Østerăs, Norway.

Reprint requests to: Dr T Tynes, Cancer Registry of Norway, Montebello, N-0310 Oslo, Norway. cell membrane properties $(3,4)$. It is not known whether peak field strength, cumulative exposure, or relative orientation of the field is important.

Two earlier Norwegian studies on cancer and exposure to EM fields have been carried out $(5,6)$. A study on cancer incidence among workers with potential exposure to EM fields showed an excess risk for leukemia for those who had been employed for long periods, but no excess risk for brain tumors was seen (5). A nested case-referent study of railroad workers gave no support to the hypothesis that EM fields can promote cancer (6). The purpose of the present study was to use calculated cumulative exposure to magnetic fields to determine whether exposure to EM fields during the production and distribution of hydroelectric power is associated with cancer.

\section{Subjects and methods}

The study cohort consisted of 5088 male workers in eight large Norwegian hydroelectric power companies. Their job title indicated exposure to electric and magnetic fields, they had been employed for at least one year, and they had been first employed between 1 January 1920 and 31 December 1985. The cohort was established from employment records available 
at each company. The completeness was not guaranteed for employees dead or retired before 1950 . The two largest companies contributed more than $50 \%$ of the cohort. The records varied greatly from company to company but generally included the following information: name, personal identification number, gender, date of birth, date of leaving, and summary of work history. For some employees information on jobs held before hire at the present company were also available. Information on whether a man had ever smoked was also collected, although this information was not available for $12 \%$ of the cohort. Among the cohort members with such information available, $70 \%$ were smokers or exsmokers and $30 \%$ had never smoked.

All new cases of cancer in Norway have been recorded by the Cancer Registry since 1953 (7). The system is based on compulsory reporting by hospital departments and histopathological laboratories. All causes of death on death certificates are coded by the Central Bureau of Statistics and reported regularly to the Cancer Registry. Cancers are coded according to the International Classification of Diseases, seventh revision. Site 193 (brain tumors) includes all tumors of the central nervous system and malignant tumors of the peripheral nervous system.

The cohort was followed from 1953 to the end of 1991 by use of the personal identification number given to all citizens alive at the census in 1960 or who were born in or immigrated to Norway later. The date of death or emigration and details of any cancer diagnosis were obtained for each individual. Only five $(0.1 \%)$ of the workers were lost to follow-up; six workers emigrated during the follow-up period.

\section{Exposure assessment}

No personal dosimeter measurements were available. The procedure for calculating exposure to magnetic fields can be described as follows: a job title list and

Table 1. Exposure to magnetic fields during an 8-h workday (typical value) for various worksites in power production and distribution, based on results of spot measurements (root mean square).

\begin{tabular}{lcccc}
\hline Worksite & $\begin{array}{c}\text { Minimum } \\
(\mu \mathrm{T})\end{array}$ & $\begin{array}{c}\text { Maximum } \\
\langle\mu \mathrm{T})\end{array}$ & $\begin{array}{c}\text { Typical } \\
\text { value, } \\
(\boldsymbol{\mu} \mathrm{T})\end{array}$ & $\begin{array}{c}\text { Time } \\
\text { spent at } \\
\text { site }(\%)\end{array}$ \\
\hline Power stations & & & & \\
$\quad$ Control room & 0.3 & 126 & 2 &. \\
Repair room & 0.5 & 20 & 1 &. \\
Indoor station & 0.3 & 200 & 5 &. \\
$\quad$ Lunchroom & 0.5 & 40 & 2 &. \\
Outdoor station & 0.5 & 10 & 3 &. \\
Under electric lines & & & & \\
0-13 kV & 0.1 & 3 & 0.5 & 60 \\
14-47 kV & 0.5 & 10 & 5 & 40 \\
50-420 kV & 1 & 20 & 8 & 20 \\
Other installations & & & & \\
Transformer & 1 & 100 & 10 & 70 \\
Cable & 0.1 & 20 & 0.8 & 50 \\
Road lights & 0.1 & 0.5 & 0.2 &. \\
Central switch & 0.1 & 5 & 1 &. \\
\hline
\end{tabular}

job description was drawn up for each power company by long-time employees who could recall the time spent at different work sites and relevant exposures in the job. All job titles with possible exposure to ELF EM fields were included. Spot measurements (root mean square) of magnetic fields were performed by two experienced electrical engineers at current worksites in the two larger power companies, and the results were used to determine a typical value (table 1). This information was combined with the job descriptions to establish current and past time-weighted-average exposure to magnetic fields (in microteslas) for each job title on the list. A category value (four levels) for electric fields was also included according to maximum voltage in each job title. Other exposures, such as solvents, herbicides, asbestos, and cable oils, were also included in the job title list with the use of four levels according to frequency of exposure (never, monthly, weekly, and daily).

\section{Work history}

In each company retired or current workers who had good knowledge of historical data examined the employment records from company files to provide work histories (all jobs held by each cohort member). The work histories were then coded according to the job title list and merged with the exposure data. The exposure of each cohort member was accumulated from the first year of employment in an exposed job up to the year of retirement or end of follow-up to give each subject's cumulative exposure to magnetic fields (microtesla-years). Exposure to electric fields was calculated by multiplying the maximum voltage in the actual job by the number of years employed. Cumulative exposures to solvents, herbicides, asbestos, and cable oil were obtained by multiplying the exposure levels $(0,1,2$, or 3$)$ with the number of years employed. Three categories of exposure to magnetic and electric fields were formed by allocating similar numbers of person-years to each group. The average duration of employment was 22 years. Only $1 \%$ of the cohort had worked less than two years, and $48 \%$ had worked more than 20 years.

\section{Statistics}

The basic unit of statistical computation was the number of years each employee was followed from the date of first employment to the end of the study period or death. Each year contributed by each cohort member was classified by age and calendar year, and the person-years of all workers were then summed by age and calendar year. In the cohort analysis, the standardized incidence ratio (SIR) for total cancer is given with the national male population as the reference entity. The expected number of cancer cases was calculated from the five-year, age-specific incidence rates for the reference entity for each year of follow-up (1953-1991). Ninety-five percent con- 
fidence intervals $(95 \% \mathrm{CI})$ were determined on the assumption of a Poisson distribution of the observed number of cancer cases and the use of a two-sided test of significance; a result was regarded as statistically significant if the $95 \%$ confidence interval did not include 100 . The actual computation was performed with a standard computer program (8).

\section{Results}

\section{Total cohort}

During the follow-up period 1953-1991 (116930 person-years), 486 new cases of cancer were observed (table 2). No significant change in risk was seen for cancer at any site. The standardized incidence ratio was lower than unity for malignant lymphoma and greater than unity for stomach cancer and nonmelanoma skin cancer.

\section{Analysis by time since first employment and duration of employment}

An analysis of all cancers, brain tumors, and leukemia by time since first employment (data not shown) showed no change in incidence. For stomach cancer an excess risk was shown for workers with more than 30 years since first employment, and a rise in the standardized incidence ratio was detected for malignant melanoma (the SIR rose from 73 in the category $<20$ years since first employment to 131 in the category $>30$ years since first employment). An analysis by duration of employment (table 3 ) showed a rise in the standardized incidence ratio for all cancers combined, cancer of the pancreas, lung (significant linear trend, Poisson trend statistics) and kidney, malignant melanoma, nonmelanoma, and lymphoma.

\section{Analysis by longest held job}

Table 4 shows the number of cases of all cancer and the number for selected sites for groups of job categories. The excess risk for cancer at all sites for installation electricians was not associated with duration of employment (data not shown). Two of the three cases of leukemia among the installation electricians occurred in workers who had been employed for less than 20 years. An elevated risk for nonmelanoma skin cancer was seen for installation electricians (data not shown, 3 observed, SIR 197) and for the "other worker" group (7 observed, SIR 175).

\section{Analysis by cumulative exposure}

Table 5 shows the number of observed cases of cancer and the standardized incidence ratios for selected cancer sites by calculated levels of exposure to cumulative magnetic fields. An excess risk was seen for malignant melanoma at cumulative exposures above $35 \mu \mathrm{T}$-years, although the data showed no continuous exposure-response trend. No association with magnetic fields was seen for leukemia, and brain tumor showed a tendency towards a negative correlation. An analysis by calculated levels of exposure to electric fields showed no association for any site (data not shown). The cumulative categorized data on workers possibly exposed to electric discharges showed no association for either leukemia or brain tumors (data not shown). The evaluation of risk for malignant melanoma and combined exposures to magnetic fields and possible exposure to electric discharges or to oils contaminated with polychlorinated biphenyls (PCB) showed a tendency towards an effect (table 6). The standardized incidence ratio for lung cancer was analyzed

Table 2. Numbers of observed $(0)$ new cases of cancer among 5088 Norwegian power plant workers and their standardized incidence ratios (SIR) and $95 \%$ confidence intervals $(95 \% \mathrm{Cl}$ ) $-1953-1991$.

\begin{tabular}{lrrr}
\hline Site of cancer $^{\mathrm{a}}$ & 0 & SIR & $95 \% \mathrm{CI}$ \\
\hline Stomach (151) & 57 & 130 & $99-169$ \\
Colon (153) & 39 & 103 & $73-141$ \\
Rectum (154) & 27 & 106 & $70-155$ \\
Pancreas (157) & 19 & 109 & $66-170$ \\
Lung (162) & 68 & 111 & $86-140$ \\
Breast (170) & 1 & 137 & $3-763$ \\
Prostate (177) & 90 & 108 & $86-132$ \\
Kidney (180) & 19 & 108 & $65-168$ \\
Bladder (181) & 27 & 83 & $54-120$ \\
Malignant melanoma (190) & 19 & 112 & $67-175$ \\
Nonmelanoma (191) & 18 & 129 & $77-204$ \\
Brain tumor (193) & 13 & 88 & $47-150$ \\
Lymphoma (201) & 12 & 68 & $35-119$ \\
Leukemia (204) & 11 & 90 & $45-160$ \\
Other & 66 & 81 & $62-103$ \\
\hline All cancers & 486 & 100 & $92-110$ \\
\hline
\end{tabular}

a Code of the International Classification of Diseases, seventh revision, in parentheses.

Table 3. Numbers of observed $(O)$ cases of cancer at selected sites among 5088 Norwegian power plant workers and the standardized incidence ratios (SIR) by duration of employment follow-up from 1953 to 1991.

\begin{tabular}{|c|c|c|c|c|c|c|}
\hline \multirow{3}{*}{ Site of cancera } & \multicolumn{6}{|c|}{ Duration of employment } \\
\hline & \multicolumn{2}{|c|}{$<10$ years } & \multicolumn{2}{|c|}{$10-29$ years } & \multicolumn{2}{|c|}{$>30$ years } \\
\hline & 0 & SIR & 0 & SIR & 0 & SIR \\
\hline Stomach (151) & 6 & 140 & 20 & 119 & 31 & 137 \\
\hline Colon (153) & 6 & 150 & 9 & 60 & 24 & 127 \\
\hline Pancreas (157) & 1 & 59 & 6 & 88 & 12 & 135 \\
\hline Lung (162) & 3 & 45 & 27 & 107 & 38 & 129 \\
\hline Prostate (177) & 4 & 69 & 34 & 117 & 52 & 106 \\
\hline Kidney (180) & 0 & 0 & 6 & 81 & 16 & $160^{*}$ \\
\hline Bladder (181) & 3 & 91 & 8 & 62 & 16 & 97 \\
\hline $\begin{array}{l}\text { Malignant } \\
\text { melanoma (190) }\end{array}$ & 1 & 27 & 8 & 98 & 10 & 196 \\
\hline Nonmelanoma (191) & 1 & 76 & 2 & 38 & 15 & $203^{*}$ \\
\hline Brain tumors (193) & 3 & 91 & 7 & 100 & 3 & 65 \\
\hline Lymphoma (200-2) & 0 & 0 & 6 & 79 & 6 & 92 \\
\hline Leukemia (204) & 1 & 56 & 6 & 122 & 4 & 73 \\
\hline All cancers & 48 & 83 & 168 & 87 & 270 & $115^{*}$ \\
\hline
\end{tabular}

a Code of the International Classification of Diseases, seventh revision, in parentheses.

b $\mathrm{P}<0.05$ 
Table 4. Numbers of observed $(0)$ cases of cancer at selected sites among 5088 Norwegian power plant workers and the standardized incidence ratios (SIR) by longest job held - follow-up from 1953 to 1991 .

\begin{tabular}{|c|c|c|c|c|c|c|c|c|c|c|c|c|}
\hline \multirow[t]{2}{*}{ Job title } & \multicolumn{2}{|c|}{ All sites } & \multicolumn{2}{|c|}{$\begin{array}{l}\text { Lung } \\
162\end{array}$} & \multicolumn{2}{|c|}{$\begin{array}{c}\text { Malignant } \\
\text { melanoma } \\
190\end{array}$} & \multicolumn{2}{|c|}{$\begin{array}{c}\text { Brain } \\
\text { tumors } \\
193\end{array}$} & \multicolumn{2}{|c|}{$\begin{array}{l}\text { Lymphoma } \\
200-2\end{array}$} & \multicolumn{2}{|c|}{$\begin{array}{l}\text { Leukemia } \\
204\end{array}$} \\
\hline & 0 & SIR & 0 & SIR & 0 & SIR & 0 & SIR & 0 & SIR & 0 & SIR \\
\hline $\begin{array}{l}\text { Electrician, installation } \\
\text { Electrician, power supply } \\
\text { Electric line worker } \\
\text { Power plant operator } \\
\text { Engineer } \\
\text { Other worker }\end{array}$ & $\begin{array}{r}78 \\
129 \\
46 \\
49 \\
42 \\
142\end{array}$ & $\begin{array}{c}140^{*} \\
98 \\
67^{\star} \\
88 \\
116 \\
103\end{array}$ & $\begin{array}{r}13 \\
13 \\
7 \\
10 \\
4 \\
41\end{array}$ & $\begin{array}{r}188^{\star} \\
79 \\
84 \\
137 \\
91 \\
117\end{array}$ & $\begin{array}{r}2 \\
11 \\
2 \\
2 \\
-2\end{array}$ & $\begin{array}{c}103 \\
208^{*} \\
91 \\
100 \\
0 \\
47\end{array}$ & $\begin{array}{l}2 \\
4 \\
1 \\
2 \\
2 \\
2\end{array}$ & $\begin{array}{r}111 \\
89 \\
53 \\
118 \\
182 \\
53\end{array}$ & $\begin{array}{r}1 \\
4 \\
1 \\
2 \\
4\end{array}$ & $\begin{array}{r}48 \\
77 \\
42 \\
100 \\
0 \\
87\end{array}$ & $\begin{array}{r}3 \\
3 \\
0 \\
1 \\
-4\end{array}$ & $\begin{array}{r}200 \\
88 \\
0 \\
71 \\
0 \\
121\end{array}$ \\
\hline
\end{tabular}

$* P<0.05$.

Table 5. Numbers of observed $(0)$ cases of cancer at selected sites among 5088 Norwegian power plant workers and the standardized incidence ratios (SIR) by exposure to cumulative magnetic fields - follow-up from 1953 to 1991.

\begin{tabular}{|c|c|c|c|c|c|c|}
\hline \multirow{3}{*}{ Site of cancera } & \multicolumn{6}{|c|}{$\begin{array}{c}\text { Cumulative exposure to } \\
\text { magnetic fields }\end{array}$} \\
\hline & \multicolumn{2}{|c|}{$\begin{array}{c}<5 \\
\mu T \text {-years }\end{array}$} & \multicolumn{2}{|c|}{$\begin{array}{c}5-35 \\
\mu T \text {-years }\end{array}$} & \multicolumn{2}{|c|}{$\begin{array}{c}>35 \\
\mu \mathrm{T} \text {-years }\end{array}$} \\
\hline & 0 & SIR & 0 & SIR & 0 & SIR \\
\hline Stomach (151) & 11 & 177 & 24 & 129 & 22 & 116 \\
\hline Colon & 8 & 119 & 16 & 102 & 15 & 97 \\
\hline Pancreas (157) & 4 & 145 & 5 & 68 & 10 & 135 \\
\hline Lung (162) & 11 & 101 & 25 & 97 & 32 & 129 \\
\hline Prostate (177) & 11 & 86 & 38 & 116 & 41 & 108 \\
\hline & 6 & 188 & 5 & 67 & 8 & 116 \\
\hline Bladder (181) & 3 & 52 & 15 & 112 & 9 & 67 \\
\hline Malignant melanoma $(190)$ & 3 & 71 & 5 & 63 & 11 & $224^{*}$ \\
\hline Nonmelanoma (191) & 5 & 192 & 4 & 73 & 9 & 155 \\
\hline Brain tumors (193) & 6 & 182 & 5 & 71 & 2 & 44 \\
\hline Lymphoma $(200-2)$ & 1 & 26 & 4 & 50 & 7 & 121 \\
\hline Leukemia (204) & 2 & 95 & 4 & 74 & 5 & 104 \\
\hline All cancers & 87 & 102 & 194 & 95 & 205 & 105 \\
\hline
\end{tabular}

a Code of International Classification of Diseases, seventh revision, in parentheses.

- $\mathrm{P}<0.05$.

Table 6. Numbers of observed $(\mathrm{O})$ cases of malignant melanoma among 5088 Norwegian power plant workers and the standardized incidence ratios (SIR) by exposure to polychlorinated biphenyls (PCB), cumulative magnetic fields, and electric discharges - follow-up from 1953 to 1991.

\begin{tabular}{|c|c|c|c|c|c|c|}
\hline \multirow[t]{2}{*}{ Exposure } & \multicolumn{2}{|c|}{$\begin{array}{l}\text { Never } \\
\text { exposure } \\
\text { to PCB }\end{array}$} & \multicolumn{2}{|c|}{$\begin{array}{l}\text { Ever } \\
\text { exposure } \\
\text { to PCB }\end{array}$} & \multicolumn{2}{|c|}{ Total } \\
\hline & 0 & SIR & 0 & SIR & 0 & $\operatorname{SIR}$ \\
\hline \multicolumn{7}{|l|}{ Magnetic fields } \\
\hline $\begin{array}{l}0-15 \mu \mathrm{T} \text {-years } \\
>15 \mu \mathrm{T} \text {-years }\end{array}$ & $\begin{array}{l}4 \\
6\end{array}$ & $\begin{array}{r}58 \\
118\end{array}$ & $\begin{array}{l}0 \\
9\end{array}$ & $\begin{array}{r}0 \\
265^{*}\end{array}$ & $\begin{array}{r}4 \\
15\end{array}$ & $\begin{array}{r}48 \\
178\end{array}$ \\
\hline Total & 10 & 83 & 9 & 184 & 19 & 112 \\
\hline \multicolumn{7}{|l|}{ Electric discharges } \\
\hline $\begin{array}{l}0 \text { exposure-years } \\
1-30 \text { exposure-years } \\
>30 \text { exposure-years }\end{array}$ & $\begin{array}{l}1 \\
3 \\
6 \\
\end{array}$ & $\begin{array}{r}24 \\
69 \\
171 \\
\end{array}$ & $\begin{array}{l}0 \\
2 \\
7 \\
\end{array}$ & $\begin{array}{r}0 \\
86 \\
280^{*} \\
\end{array}$ & $\begin{array}{r}1 \\
5 \\
13 \\
\end{array}$ & $\begin{array}{r}23 \\
75 \\
216 \\
\end{array}$ \\
\hline Total & 10 & 82 & 9 & 183 & 19 & 112 \\
\hline
\end{tabular}

- $\mathrm{P}<0.05$.

for combined exposure to asbestos and oil-impregnated cables. No significant association was seen, although there was an increased standardized incidence ratio for the combination more than 20 years of exposure to asbestos and more than 30 years of exposure to oil-impregnated cable (20 observed, SIR 163). The observed number of cases of lung cancer among ever smokers was 55 (SIR 137, 95\% CI 103-178). Neither bladder cancer nor leukemia showed any association with smoking.

\section{Discussion}

The present study showed no association between the occurrence of leukemia or brain tumors and exposure to electric or magnetic fields in hydroelectric power companies. No exposure-response trend was shown for cancer at any site in relation to cumulative exposures to magnetic fields, although there was an excess risk for malignant melanoma in the highest exposure category. For brain tumors, a tendency was seen towards a negative correlation with magnetic fields.

This study had the following strengths: (i) complete data with detailed job histories from employment records from the eight participating power companies and (ii) cancer incidence data from a highquality national cancer register. Exposure was determined on the basis of job title and department, however, and not from direct recordings for each individual; historical records do not give information on differences among workers within the same job category. The calculated cumulative exposure to magnetic and electric fields is, at best, a qualified estimate and may have introduced misclassification that is nondifferential (ie, independent of the end point) and in practice may have a magnitude and direction such that a linear, true exposure-response relationship would be distorted so as to appear inconsistent with causation (ie, to bias the risk estimates towards unity) (9).

Magnetic fields near high-voltage power distribution systems change less over time than those associated with other electric installations (eg, railroads and some electric appliances). Very few of the workers (less than 10\%) in our study had exposure to magnetic fields greater than $2 \mu \mathrm{T}$. An earlier study of leukemia and brain tumors in Norwegian railroad line 
workers, who experience an average 8-h timeweighted exposure to magnetic fields of $20 \mu \mathrm{T}$ (frequency $162 / 3 \mathrm{~Hz}$ ), showed no association (6). Workers in power companies are exposed to a varying degree to electrical shocks or electrical spark discharges. Discharges have been suggested to be associated with an increased frequency of chromosome aberrations $(10,11)$. In our study, however, no association was seen for either leukemia or brain tumor with categorized data on the possibility of such exposure. Although we controlled for categorized exposures to solvents, herbicides, and cable oils in our analysis, a potential confounding effect of these parameters cannot be excluded. As the exposure data were based on information from experienced current and retired workers and no historical measurements were available, misclassification may have occurred.

The selection of reference rates in occupational epidemiologic cohort studies may be problematic when cancer incidence at selected sites has a geographic gradient. The incidence of cancer in urban areas in Norway is $20 \%$ higher than in rural areas (12). The fraction of urban residency in this cohort was $10 \%$ higher than that of the general male Norwegian population. A deficit of total cancer would therefore appear in our cohort if residency were taken into consideration. The null effect in our study may reflect a possible "healthy worker effect" for selection into exposed occupations, for an incidence study on cancer this is, however, not very likely, especially not for leukemia and brain tumors.

Previous epidemiologic studies on leukemia risk among electrical workers have shown an association with such work, but most studies have not provided any evidence of a quantitative exposure-response relationship between risk and the level of EM field exposure (13-16). An exception is a Swedish casereferent study of leukemia and brain tumor, which showed an association between magnetic field measurements (dosimeter) and leukemia; for chronic lymphocytic leukemia in particular, a clear association with exposure intensity was observed (17). A recent cohort and nested-case referent study of electric utility workers, however, showed no consistent association between such work and leukemia, brain cancer, or lymphoma (18). The Norwegian census study of the incidence of cancer among workers potentially exposed to EM fields showed a $40 \%$ excess risk for leukemia in workers with a long duration of employment (5). The finding that electricians in power supply and electric line workers show elevated risks was not confirmed in the present study. Our cohort was relatively young, and at the end of the observation period (31 December 1991) 4099 (80.5\%) cohort members were still alive. The census cohort was, on the average, older ( $72 \%$ still alive at the end of the observation period), but the excess leukemia risk was not restricted to the older cohort members. Our cohort covers the largest Norwegian hydroelectric power producers and distributors, presumably with a more specialized work force than the census cohort. In addition only a smaller fraction of the workers in our cohort was present in the census cohort, which had only $20 \%$ of the power supply electricians, $15 \%$ of the power plant operators, and 5\% of the installation electricians and electric line workers. The excess risk seen previously for leukemia may therefore have occurred in similar jobs in smaller companies where there is possibly higher exposure to other factors that contribute to leukemia risk, such as, for example, solvents.

An association between electrical work and brain tumors has also been reported in previous epidemiologic studies $(14-16,19-21)$ although negative results have also emerged $(22,23)$. The Norwegian census cohort study (5) showed no excess risk for brain tumors among electrical workers, and our findings do not support the hypothesis that exposure to electric or magnetic fields in power companies enhances the risk for brain tumor.

Previous studies have drawn attention to the possibility that melanoma might be related to EM fields. Studies in telecommunications and the electronic and electrical manufacturing industry have shown excess risks for malignant melanoma (24-27). Exposure to magnetic fields has been associated with changes in the diurnal pattern of the pineal hormone melatonin (4). The patterns for malignant melanoma in our data may indicate a tendency towards an interaction between exposure to polychlorinated biphenyls and other exposures, in particular exposure to electric sparks and magnetic fields (table 6). Nine of 11 cases among electricians in power supply were possibly exposed to polychlorinated biphenyls. As polychlorinated biphenyls were used as dielectric fluids in electrical capacitors until 1977, accidental exposure may have occurred owing to explosions or the destruction of old equipment. An association between exposure to polychlorinated biphenyls and mortality from malignant melanoma has been suggested previously (28). The creation of polychlorinated dibenzofurans or other organochlorine compounds from combined exposure to polychlorinated biphenyls and electric sparks may be a mechanism of interest (table 6).

An association has been reported between lung cancer and exposure to mineral oils (29). Our data gave no opportunity to confirm this finding, although a tendency towards an association was seen.

\section{Concluding remarks}

In summary, the results of this study give no support to previous findings of a possible association between exposure to electrical and magnetic fields and leukemia and brain tumors. The results for malignant melanoma should be evaluated in future studies. Our results are based on a combination of data from a high-quality national cancer register and detailed job histories obtained from employment 
records. These advantages must be weighed against the limitations of lack of historical dosimeter data for relevant exposures and limited knowledge about the biological effects of EM fields. As the classification of cumulative exposure to magnetic fields in this study may be an imprecise surrogate for a true biologically effective exposure, the results should be interpreted with caution.

\section{Acknowledgments}

We thank the participating companies and their retired workers for cooperating in the project. We also thank Mr A Espeset and Mr E Smith, who provided the measurements of magnetic fields.

\section{References}

1. Coleman M, Beral VA. A review of epidemiological studies of the health effects of living near or working with electricity generation and transmission equipment. Int J Epidemiol 1988;17:1-13.

2. National Radiological Protection Board. Electromagnetic fields and the risk of cancer. Oxford: National Radiological Protection Board, 1992:3(1).

3. Nair I, Granger Morgan M, Keith Florig H. Biological effects of power frequency electric and magnetic fields - background paper. Washington DC: US Congress, Office of Technology Assessment, 1989.

4. Wilson BW, Anderson LE, Stevens R. Extremely low frequency electromagnetic fields: The question of cancer. Columbus, OH: Batelle Press, 1990.

5. Tynes T, Andersen A, Langmark F. Incidence of cancer in Norwegian workers potentially exposed to electromagnetic fields. Am J Epidemiol 1992;136(1):818.

6. Tynes T, Jynge H, Vistnes AI. Leukaemia and brain tumors in Norwegian railway workers, a nested casecontrol study. Am J Epidemiol. In press.

7. Pedersen $E$, Magnus $K$. Cancer Registration in Norway, 1953-54. Oslo: Norwegian Cancer Society, 1959.

8. Preston DL, Lubin JH, Pierce DA. EPICURE risk regression and data analysis software. Seattle, WA: HiroSoft International Corporation 1992.

9. Delpizzo V. An apparently incongruous exposure-response relationship resulting from use of job description to assess magnetic field exposure. Scand J Work Environ Health 1992;18:242-5.

10. Nordenson I, Hanson Mild K, Osman U, Ljungberg $\mathrm{H}$. Chromosomal effects in lymphocytes of $400 \mathrm{kV}$ substation workers. Radiat Environ Biophys 1988;27: $39-47$.

11. Skyberg K, Hansteen I-L, Vistnes AI. Chromosome aberrations in lymphocytes of high-voltage laboratory cable splicers exposed to electromagnetic fields. Scand J Work Environ Health 1993;19:29—34.

12. Cancer Registry of Norway. The incidence of cancer in Norway 1982 - 86. Oslo: Cancer Registry of Norway, 1989

13. Juutilainen J, Läärä E, Pukkala E. Incidence of leukemia and brain tumors in Finnish workers exposed to extremely low frequency magnetic fields. Occup Environ Health 1990;62;289-93.

14. Törnqvist S, Knave B, Ahlbom A, Persson T. Incidence of leukemia and brain tumors in some "electrical occupations." Br J Ind Med 1991;48:597-603.

15. Loomis DP, Savitz DA. Mortality from brain cancer and leukemia among electrical workers. Br J Ind Med 1990;47:633-8.

16. Pearce N, Reif J, Fraser J. Case-control studies of cancer in New Zealand electrical workers. Int J Epidemiol 1989;18:55-9.

17. Floderus B, Persson T, Stenlund C, Wennberg A, Öst $\AA$, Knave B. Occupational exposure to electromagnetic fields in relation to leukemia and brain tumors: a case control study in Sweden. Cancer Causes Control 1993; 4:465-76.

18. Sahl JD, Kelsh MA, Greenland S. Cohort and nested case-control studies of hematopoietic cancers and brain cancer among electric utility workers. Epidemiology 1993;4(2):104-14.

19. Lin RS, Dischinger PC, Conde J, Farrell KP. Occupational exposure to electromagnetic fields and the occurrence of brain tumor: an analysis of possible associations. J Occup Med 1985;27:413-9.

20. Preston-Martin S, Henderson BE, Peters JM. Descriptive epidemiology of central nervous system neoplasms in Los Angeles County. Ann NY Acad Sci 1982:381; 202-8.

21. Speers M, Dobbins JG, Miller VS. Occupational exposure and brain cancer mortality: a preliminary study of east Texas residents. Am J Ind Med 1988:13;629 38.

22. Thomas TL, Stolley PD, Stemhagen A, Fontham ET, Bieecker ML, Stewart PA, et al. Brain tumors mortality risk among men with electric and electronics jobs: a case control study. JNCI 1987;79: 233-8.

23. McLaughlin JK, Malker HS, Blot WJ, Malker BK, Stone BJ, Weiner JA, et al. Occupational risk for intracranial gliomas in Sweden. JNCI 1987:78;253-7.

24. Vågerö D, Ahlbom A, Olin R, Ahlsten S. Cancer morbidity among workers in the telecommunications industry. Br J Ind Med 1985;42:191—6.

25. Vågerö $D$, Olin $R$. Incidence of cancer in the electronics industry: using the new Swedish Cancer Environment Registry. Br J Ind Med 1983;40:188-92.

26. Sorahan T, Waterhouse JA, McKiernan MJ, Aston RH Cancer incidence and cancer mortality in a cohort of semiconductor workers. Br J Ind Med 1985;42:54650.

27. De Guire L, Thériault G, Iturra H, Provencher S, Syr $\mathrm{D}$, Case $\mathrm{BW}$. Increased incidence of malignant melanoma of the skin in workers in a telecommunications industry. Br J Ind Med 1988;45:824-8.

28. Sinks T, Smith AB, Rinsky R, Watkins K, Shults R, Steele G. Health hazard evaluation report, Westinghouse Electric Corporation, Bloomington, Indiana. Cincinnati, $\mathrm{OH}$ : National Institute for Occupational Safety and Health, 1991. Report no HETA-89$116-2094$.

29. Rønneberg A, Andersen A, Skyberg K. Mortality and incidence of cancer among oil exposed workers in a Norwegian cable manufacturing company: part 2 . mortality and cancer incidence $1953-84 . \mathrm{Br} \mathrm{J}$ Ind Med $1988 ; 45: 595-601$.

Received for publication: 4 October 1993 